\title{
Cultura, folclore y tradición: reflexiones en torno a la vida y obra de Manuel Dannemann Rothstein (Santiago, 1932- 2021)
}

\section{Culture, folklore and tradition. Reflections on the life and work of Manuel Dannemann Rothstein (Santiago, 1932-2021)}

\author{
por \\ Christian Spencer Espinosa \\ Centro de Investigación en Artes y Humanidades (CIAH) \\ Facultad de Artes, Universidad Mayor, Chile \\ christian.spencer@umayor.cl
}

Filólogo, etnólogo y etnomusicólogo, Manuel Teodoro Dannemann Rothstein es uno de los investigadores más importantes de la cultura tradicional chilena del siglo XX. Realizó sus estudios primarios y secundarios en el Liceo Alemán y en el Colegio Verbo Divino, se tituló como profesor de castellano y completó su Doctorado en Literatura con mención en Literatura Chilena e Hispanoamericana en la Universidad de Chile. Como etnomusicólogo se formó con el compositor y musicólogo Carlos Lavín, y recibió orientaciones metodológicas del especialista español en historia de la música, Vicente Salas Viu. Posteriormente realizó cursos en Alemania y Estados Unidos sobre folclore y cultura tradicional, algunos de cuyos contenidos aplicó en sus publicaciones.

La labor de Dannemann se desplegó en el ámbito de la investigación y las publicaciones, la docencia, la recolección de música, la gestión y promoción de las instituciones y la difusión internacional de la poesía popular y el folclore chileno. Estuvo activo durante más de medio siglo, por lo que su obra traspasa varias generaciones en los ámbitos de la etnología, la etnomusicología y la antropología. Sus publicaciones y charlas ascienden a más de un centenar, mientras que sus proyectos de investigación superan la decena, y su labor docente cruza la segunda mitad del siglo XX para instalarse en los cambios culturales del siglo XXI. En el ámbito internacional, fue profesor visitante de la Universidad Complutense de Madrid, la Universidad de Indiana en Estados Unidos, la Universidad de Buenos Aires, la Universidad de Salta y la Universidad Nacional de Salta, en Argentina. También llegó a ser invitado por el Instituto Interamericano de Etnomusicología y Folclor (INIDEF) debido a su coordinación de las tres misiones de relevamiento etnomusicológico y folclórico que este instituto llevó a cabo junto con la Universidad de Chile y la Organización de Estados Americanos (OEA) entre 1977 y 1978 (Dannemann 1978). Fue becario de la fundación Guggenheim en 1978, mismo año que lo fuera el destacado biólogo chileno Humberto Maturana Romesín, fallecido este mismo año 2021. En 2019 curó e inauguró el Museo de la Vivienda Tradicional Local en el Bosque de Santiago del Parque Metropolitano, cerrando una faceta menos conocida de su labor antropológica acerca de las manifestaciones tradicionales de base empírica en el país.

Su filiación y vida profesional se desarrollaron en torno a la Universidad de Chile, donde alcanzó el grado de profesor titular en 1986. Fue profesor del Departamento de Antropología de la Facultad de Filosofía, Humanidades y Educación, profesor de la Facultad de Ciencias y Artes Musicales en sus diversas etapas y nombres (1960-1990) y maestro de la Facultad de Ciencias Sociales (FACSO) de esta misma 
casa de estudios. En esta última fue fundador y profesor de la Cátedra de Folclore Musical (Facultad de Artes), y en la Facultad de Filosofía y Ciencias de la Educación de la Pontificia Universidad Católica de Chile impartió la Cátedra de Folclore General y Chileno. Fungió como director del Instituto de Investigaciones Musicales de la Universidad de Chile, fue coordinador del Seminario Interfacultades "El folclor como cultura" hasta mediados de la década de 2010, y presidió el Programa de Desarrollo de Identidades Culturales radicado en el Departamento de Antropología de la FACSO. También integró la International Society of Folk Narrative Research, la Sociedad Internacional de Etnología y Folklore y fue miembro de la Sociedad Chilena de Historia y Geografía (SChHG), cuya revista dirigió. $\mathrm{Al}$ interior de esta última, refundió en 1982 la antigua Sociedad de Folklore Chileno bajo el nombre "Sección de Folklore de la Sociedad Chilena de Historia y Geografía", la que se mantuvo activa hasta al menos la primera década del siglo XXI.

En el ámbito de la gestión, fue presidente de la Comisión Chilena del Instituto Andino de Artes Populares (Convenio Andrés Bello), coordinador de la Bibliografía Internacional de Folclor para América Latina y Director de la Sección de Folclore de la SChHG. También llegó a ser director de la Revista Chilena de Antropología y la Revista Chilena de Historia y Geografia, siendo colaborador fundamental de la Revista Musical Chilena entre 1960 y 1978 (con colaboraciones esporádicas entre 1994 y 2015), entre otras revistas latinoamericanas donde participó como parte de su comité editorial. Más recientemente, formó parte del jurado evaluador de los Fondos Concursables del Consejo Nacional de la Cultura y las Artes (CNCA 2006) y en sus últimos años dirigió la Corporación de Desarrollo Cultural de Algarrobo, en el litoral de Chile.

Como etnólogo, Dannemann no solo coordinó las mencionadas misiones de relevamiento etnomusicológico. También fue investigador del proyecto UNESCO sobre música tradicional de Chile con el cual produjo los discos Amerindian Ceremonial Music From Chile y también Hispano-Chilean Metisse Traditional Music (1976). En su función de recolector, se ocupó de revitalizar la práctica de algunas músicas tradicionales en Puente Alto, Lora y Melipilla, alcanzando a ver la reactualización empírica de algunas de sus actividades musicales en vida (García 1999). Aunque existe poca información acerca de la relación que Dannemann establecía con los cultores, sus nexos parecen haber estado signados por el carácter científico de su trabajo, ahondando menos en las cuestiones humanitarias de estos (propias de la etnología y la antropología cultural) y más en el trabajo de registro y escritura del trabajo de campo. Este hecho probablemente explique la abundante presencia de biografías de académicos y la escasa presencia de la vida y obra de cultores o folcloristas en sus publicaciones, con la excepción de su monografía Vida y obra del poeta popular Vicente Salazar (2000).

Un aspecto central del aporte de este investigador a la cultura chilena fue su dirección del Atlas del Folklore Chileno (1972-1982), uno de los primeros proyectos multidisciplinarios de aproximación al folclore. Aunque el proyecto no llegó a concretarse del todo, su objetivo principal resumió bien el espíritu de una época preocupada de conocer las supervivencias musicales: "entender la cultura musical mestiza y aborigen en su medio y en su trayectoria histórica, con una marcada intención de comprobar su función social" (Bustos 1988: 31). El proyecto contó con el apoyo del International Council for Traditional Music (ICTM) y registró profusamente músicas y bailes folclóricos del país, algunos de ellos audiovisualmente (Montecinos en Lennon 2021). El "Plan Multinacional de Relevamiento Etnomusicológico y Folklórico”, como se llamó originalmente, contó con al menos tres misiones etnomusicológicas que se desplegaron en más de 250 localidades del país (García 1999), donde los expertos se apoyaron en la experiencia de la Universidad de California.

\section{DANNEMANN Y EL FOLCLORE}

En el ámbito de las publicaciones, la obra de Dannemann fue profunda y generosa. Publicó biografías, reseñas, bibliografías, notas de programas y discos, capítulos de libros, libros y artículos, estos últimos escritos mayormente en español y, en menor medida, en inglés, francés y alemán. También prologó y editó libros de folcloristas connotados y coordinó seminarios docentes y tesis de pregrado que posteriormente se convirtieron en publicaciones. Heredero de la tradición explicativa alemana, su escritura y enfoque fueron marcadamente científicos, a pesar de su conocimiento de la poesía popular y sus incontables vericuetos narrativos. Sus trabajos se iniciaron hacia 1958 con el texto "Octogésimo aniversario de la fundación de The Folk-lore Society”, publicado en la Revista Musical Chilena, y llegaron hasta al menos el año 2016 con la publicación de un completo estudio preliminar acerca de la vida y obra de Ramón Laval en el libro Cuentos populares y folclóricos chilenos (Ed. Universitaria). 
En sus trabajos, Dannemann fue levantando una noción de folclore propia que terminó por configurar un verdadero paradigma cultural con impacto entre folcloristas y académicos chilenos y latinoamericanos. Desde el punto de vista teórico, desarrolló un concepto funcionalista al que fue agregando capas de complejidad que permitieran profundizarlo y actualizarlo. El folclore fue para él una forma de comportamiento (individual o comunitaria) asociada a un hecho tenido por tradicional por un conjunto de personas y en un contexto específico donde se hacía usufructo de bienes culturales. "Entiendo por folklore -dice Dannemann- el comportamiento de una comunidad folklórica; vale decir, el usufructo tradicional de los bienes culturales que, con respecto a ella, hayan adquirido la calidad funcional autónoma de comunes, propios, aglutinantes y representativos. Una comunidad folklórica aparece en un lugar determinado o no, con mayor o menor grado de esporadicidad en su constitución y de transitoriedad en su duración” (1972: 6). Como señala Marta Blache (1983: 39), Dannemann comprendió el folclore como "una clase de conducta" en la que cada uno toma "mayor o menor parte" en determinadas circunstancias. En este sentido, contribuyó a renovar las visiones esencialistas de la tradición que enfatizaban el "folk" o el "lore", situando el folclore como un "todo inestable" en su composición y rasgos. Por este motivo para Dannemann "No hay un conjunto de individuos propiamente folklóricos" sino "situaciones más o menos propicias para que el hombre participe de una conducta folklórica” (Blache 1983: 39). Esta perspectiva, similar a las sostenidas por académicos europeos y estadounidenses entre los años sesenta y ochenta, amplió el campo de estudios de la ciencia del folclore en América Latina, aportando una perspectiva más próxima a los "hechos sociales" que a "las cosas", y permitiendo dar un paso hacia adelante respecto de la antropología difusionista practicada por Carlos Vega y sus discípulos desde la década de 1930.

La concepción de folclore de Dannemann tuvo un impacto importante entre los académicos chilenos y latinoamericanos. Folcloristas, bailarines, antropólogos, etnomusicólogos e investigadores de la música tomaron sus ideas como un punto de renovación para la comprensión del folclore, especialmente a partir de la publicación del libro Teorías del Folklore en América Latina, donde Dannemann compiló y publicó - a petición del INIDEF- el texto principal del libro. Heredero de una concepción neofuncionalista del folclore tomada del historiador y folclorista alemán Richard Weiss (1907-1962), logró integrar en su concepción de lo tradicional la descripción, función y análisis de la cultura con una metodología que incluyera la comunidad y los bienes folclóricos participantes. Buena parte de su obra teórica, dispersa en publicaciones realizadas entre 1960 y 1998, es deudora de esta concepción cuyo efecto en Chile aún no ha sido dimensionado del todo, pero que con toda seguridad futuras generaciones sabrán aquilatar correctamente. En este sentido, la obra de Dannemann es sin lugar a duda una de las obras de mayor profundidad dentro de los estudios folclóricos chilenos, no solo en términos teóricos sino también en términos de su impacto entre folcloristas y académicos, no así entre cultores.

Las ideas de Dannemann acerca del folclore quedaron bien retratadas en el mencionado Atlas del Folklore Chileno, probablemente su mayor aporte como investigador a la cultura chilena y de donde emanó gran parte de su trabajo como antropólogo de la música. Este proyecto inconcluso estuvo inspirado en la obra de Weiss, quien realizara un atlas similar en Suiza en los años cincuenta, y a quien Dannemann dedicó su trabajo teórico preliminar, donde establece las bases no solo de la obra en su conjunto, sino también de su propio pensamiento folclórico (Dannemann 1969: 1). Casi cuatro décadas más tarde esta obra será objeto de críticas por parte de historiadores y etnomusicólogos, quienes le reprocharán evadir el valor político de las tradiciones e inclinar su análisis hacia la relación entre el folclore, la nación y la identidad. Dannemann alcanzará a corregir algunas de estas críticas en la edición de su Enciclopedia del Folclore de Chile (1998), donde se explayará más acerca de la vida de los cultores en un tono de menor impronta positivista. Puede decirse que Dannemann logró responder de muchas maneras la pregunta qué es el folclore, caracterizándolo y analizándolo desde distintos ángulos, pero también separándolo de las políticas públicas y concibiéndolo como un bien cultural superior, casi al margen del Estado, aunque con estatus humano y científico al mismo tiempo.

Algunas de las críticas hechas a su obra se extenderán posteriormente a tres aspectos de su trabajo: su concepción "cientificista" del folclore, más centrada en los hechos que en las personas; su atención preferencial por el valle central en desmedro de las regiones; y la concepción hispano-céntrica de su pensamiento sobre lo tradicional, con poca atención a la genealogía de las culturas indígenas (Donoso 2006). Este último aspecto, empero, será cubierto por algunos de sus trabajos posteriores, aunque sin abandonar la perspectiva etnológica neofuncionalista de su trabajo y con poca presencia de estudios de caso (Dannemann 1977; 1989; 2011). Es importante mencionar que este carácter eminentemente lógico de su obra le permitió penetrar en los medios de comunicación, consiguiendo representación en la prensa tradicional, las instituciones y en algunas revistas que otrora no consideraban expresiones tradicionales de Chile más allá de su relación con la identidad. Ejemplo de ello es su última entrevista 
publicada en 2021 (que data de 1997), donde Dannemann criticó la falta de profundidad del estudio de la cultura chilena comparándola con un baile de gala donde solo interesan "ciertas apariencias y vocabularios y no existe una relación directa con la especificidad local” (en Lennon 2021: E5).

\section{VALOR Y LEGADO DE SU OBRA}

Un aspecto que considero significativo de la obra de este intelectual fue su capacidad para enfrentar sin ambages algunos de los tópicos centrales de la cultura tradicional y musical latinoamericana. Muchos de estos temas fueron posteriormente abandonados o parcialmente abordados por otros especialistas debido a su complejidad y extensión. Entre ellos encontramos los usos y funciones del lenguaje y la narración (1980, 1987, 1998), el significado del concepto de folclore a lo largo de la historia (1974; 1976; 2007), algunos aspectos metodológicos de la investigación (1960; 1972; 1978; 1995), cuestiones teóricas del campo disciplinario (1975), historia de las instituciones ligadas al folclore (1967; 1969) o del mismo folclore en Chile $(1960 ; 1976 ; 1998 ; 2002)$ y cuestiones relativas a la organología (1960).

En todas estas actividades, Dannemann mostró un marcado sentido de continuidad en su trabajo, lo que le permitió profundizar sus ideas y argumentos en torno a la cultura tradicional. Esta habilidad parece ser propia de toda una generación de intelectuales chilenos nacidos en la primera parte del siglo XX, entre los que se encuentra el historiador de la música Eugenio Pereira Salas. No es de extrañarse, en este sentido, que Dannemann participara en proyectos de largo aliento como el mencionado Atlas, la Enciclopedia del Folclore de Chile (1998) o la edición de los Archivos del Folklore Chileno, esta última continuación de dos importantes estudiosos del folclore Rodolfo Lenz y Yolando Pino. Vale la pena recordar al respecto que la Revista de Folklore Chileno tuvo continuidad en los Archivos del Folklore Chileno (1950-1957; 1971-1976; y 2002-2008), cuya última etapa dirigió Dannemann siguiendo el mismo derrotero filosófico y etnológico de sus predecesores (Spencer, Rammsy y Contreras 2019: 35). De todas estas acciones, empero, el Atlas es la que mejor sintetiza el pensamiento y labor de Dannemann en términos metodológicos, teóricos y musicales, constituyendo una obra de referencia obligada a nivel regional, al igual que la señera edición del libro Teorías del Folklore en América Latina (1975).

Otro mérito destacable de Dannemann es haberse ocupado en sus publicaciones de algunas áreas grises de los estudios académicos locales, como las biografías y las bibliografías. Entre las primeras, destacan sus relatos acerca de la vida de Yolando Pino (1993), Rodolfo Lenz (1990; 2000), Ramón Laval (2016), Vicuña Cifuentes (junto a Lenz y Laval, 2010) y Vicente Salazar (2000), además de sus textos in memoriam dedicados a Raquel Barros (2014) y a Luis Felipe Ramón y Rivera (1994). La práctica de este género escritural fue uno de los sellos literarios de Dannemann, un formato cada vez menos frecuente en Chile donde la individualización de las carreras académicas y el progresivo abandono del sentido comunitario ha evitado progresivamente pensar la disciplina de manera colectiva. Entre sus bibliografías destacan las dedicadas al folclore chileno (1970; 1979), continuadoras directas del trabajo de Eugenio Pereira Salas, y la dedicada a la artesanía nacional (1983), además de una dedicada a Carlos Lavín (1967). En lo relativo a sus colaboraciones destaca la dupla formada con Raquel Barros, también folclorista, materializada en los textos Los problemas de la investigación del folklore musical chileno (1960), El guitarrón en el Departamento de Puente Alto (1960), Introducción al Estudio de la Tonada (1964), Guía metodológica de la investigación folklórica (1964), La ruta de la Virgen de Palo Colorado (1965) y El romancero chileno (1970), algunos de ellos señeros en su disciplina en Chile.

Desde el punto de vista académico, la obra de Manuel Dannemann constituye sin lugar a duda uno de los aportes más importantes realizados en torno al estudio del folclore, la música y las culturas tradicionales chilenas. Dannemann es no solo el único investigador local que logró formular una teoría del folclore propia -con resonancias internacionales-, sino uno de los pocos investigadores que consiguió traspasar sus conocimientos a las instituciones donde estuvo y a los estudiantes que trabajaron con él. Su muerte, junto con la de Margot Loyola, cierra un ciclo importante de los estudios folclóricos chilenos que comenzó con la creación de la Sociedad del Folklore Chileno en 1909, en un arco de más de cien años de trabajo científico y empírico en torno a la música tradicional. Queda pendiente un estudio serio acerca de su aporte a los estudios folclóricos, la antropología cultural y la etnomusicología chilena del último medio siglo ${ }^{1}$.

1 La lista de obras que se presenta a continuación no constituye una biobibliografía. Se excluyen los textos que no fueron comentados a lo largo de esta reseña de la vida y obra de Manuel Dannemann. 


\section{BIBLIOGRAFÍA}

Como autor único

1958 "Octogésimo aniversario de la fundación de The Folk-lore Society", Revista Musical Chilena, XII/60, pp. 98-99.

1960 "Los estudios folklóricos en nuestros ciento cincuenta años de vida independiente", Anales de la Universidad de Chile, CXVIII/120, pp. 203-217.

1967 "Bibliografía folklórica y etnográfica de Carlos Lavín”, Revista Musical Chilena, XXI/99, pp. 85-88.

1969 "El programa interamericano de etnomusicología”, Revista Musical Chilena, XXIII/107, pp. 3-5.

1967 "Veinte años del Instituto de Investigación Musical", Revista Musical Chilena, XXI/100, pp. 39-43.

1969 "Estudio preliminar para el atlas folklórico musical de Chile", Revista Musical Chilena, XXIII/106, pp. 7-34.

1970 Bibliografía del folklore chileno, 1952-1965. Austin: Center for Intercultural Studies in Folklore and Oral History, University of Texas.

1972 "Atlas del folklore chileno. Metodología general", Revista Musical Chilena, XXVI/118, pp. 3-21.

1974 "Estudios sobre música folklórica chilena”, Aisthesis, 8, pp. 269-305.

1975 "Teoría folklórica: planteamientos críticos y proposiciones básicas", Teorías del Folklore en América Latina, Manuel Danneman Rothstein (editor). Caracas: INIDEF/CONAC.

1976 "Nuevas reflexiones en torno al concepto de folklore", Folklore Americano, 22, pp. 121-129.

1976 "La disciplina del folklore en Chile", Archivos del Folklore Chileno, 10, pp. 23-74.

1977 "The Musical Traditions of the Indigenous Peoples of Chile", The World of Music XIX/3-4, pp. 104-113.

1978 "Plan Multinacional de Relevamiento Etnomusicológico y Folklórico", Revista Musical Chilena, $32 / 141$, pp. 17-25.

1979 "Bibliografía del folklore [1966-1979]", Revista Chilena de Antropología, II/2, pp. 7-78.

1980 "Uso elusivo y función satírica de apodos", Boletín de Filología, XXXI/2, pp. 633-645.

1987 "Una formulación teórica para el evento de narrar", Revista Chilena de Humanidades, 9, pp. 93-102.

1990 "Rodolfo Lenz, etnólogo y estudioso del folklore”, Revista Chilena de Antropología, VIII/8, pp. 77-92.

1993 "Yolando Pino Saavedra (1901-1992)", Fábula, 34 (enero), pp. 122-123.

1994 “Luis Felipe Ramón y Rivera (1913-1993)”, Revista Musical Chilena, XLVIII/181, pp. 146.

1998 “Apuntes sobre el léxico del vino chileno”, Boletín de Filología, XXXVII/1, pp. 447-458.

1998 Enciclopedia del Folclore de Chile. Eduardo Castro Le Fort (editor). Santiago: Editorial Universitaria.

2000 "Vida y obra de Rodolfo Lenz", Boletín de Filología, XXXVIII/1, pp. 331-339.

2002 "Los estudios de la cultura folclórica en Chile en el cruce de los siglos XX y XXI", Archivos del Folclore Chileno, 11, pp. 15-39. 
2007 Cultura folclórica de Chile. Ed. audiovisual. Santiago de Chile: Universitaria.

2010 "Tres buscadores de chilenidad: Lenz, Laval y Vicuña Cifuentes", Anales de Literatura Chilena, XI/14, pp. 57-92.

2011 "Las multietnias en la sociedad chilena contemporánea", Societas. Revista de la Academia Chilena de Ciencias Sociales, Políticas y Morales, 13, pp. 55-58.

2014 "Raquel Barros Aldunate (2 de diciembre,1919-11 de agosto, 2014)", Revista Musical Chilena, LXVIII/222, pp. 117-120.

Con Raquel Barros Aldunate

1960 "Los problemas de la investigación del folklore musical chileno", Revista Musical Chilena, XIV/71, pp. 82-100.

1960 El Guitarrón en el departamento de Puente Alto. Ensayos; 12. Santiago: Universidad de Chile, Instituto de Investigaciones Musicales, Facultad de Ciencias y Artes Musicales. Publicado también en Revista Musical Chilena, XIV/74 (1960), pp. 7-45.

1966 La ruta de la Virgen de Palo Colorado. Colección de ensayos / Santiago: Universidad de Chile Facultad de Ciencias y Artes Musicales, Instituto de Investigaciones Musicales. Publicado también en Revista Musical Chilena, XIX/93 (1965), pp. 6-24.

1970 El romancero chileno. Santiago: Universidad de Chile. Corresponde a Revista Musical Chilena, XXIV/111 (1970).

1964 "Guía metodológica de la investigación folklórica”, Mapocho, 1, pp. 168-178.

1964 "Introducción al estudio de la Tonada", Revista Musical Chilena, XVIII /89, pp. 105-116.

Con otros colaboradores

FuHRIMANN, Joyce.

1983 Bibliografía de la artesanía tradicional chilena. Santiago, Chile: Comisión Nacional Chilena del Instituto Andino de Artes Populares.

Madariaga, Arnoldo.

$2000 \quad$ Vida y obra del poeta popular Vicente Salazar. Santiago de Chile: [s.n.].

Valencia, Alba.

1989 Grupos aborígenes chilenos: su situación actual y distribución territorial. Colección Terra Nostra; $\mathrm{n}^{\circ}$ 15. Santiago: Instituto de Investigaciones del Patrimonio Territorial de Chile.

Ediciones

Laval Alvear, Ramón Arminio.

2016 Cuentos populares y folclóricos chilenos. Santiago, Chile: Universitaria.

Textos citados de otras autorías

Blache, Marta.

1983 “Conceptualización del folklore en Hispanoamérica y en la Argentina”, Aisthesis, 15, pp. 37-46.

Bustos, RaQuel.

1988 "La musicología en Chile: la presente década", Revista Musical Chilena, LII /169, pp. 27-36.

GARCÍA, FERNANDO.

1999 "Manuel Teodoro Dannemann”. Diccionario de la Música Española e Hispanoamericana, Emilio Casares (editor), pp. 358-359. Madrid: SGAE. 
Lennon, Maureen.

2021 "Manuel Dannemann: el legado de un amante del campo, las raíces y la poesía popular", El Mercurio (18 de abril), E5, Artes y Letras.

Spencer, Christian, Antonieta Contreras y Gabriel Rammsy.

2019 "Historia, producción y continuidad de la Sociedad de Folklore Chileno (1909-2008)", Recial, X/16, pp. 18-41. 